\title{
Dry Eye- Study of Prevalence, Associated Risk Factors and Frequency of Symptoms in Meerut District
}

\author{
S. Attri' ${ }^{1}$, J. Dwivedi², S. Mithal ${ }^{3}$, A. Gupta ${ }^{4}$, L.K. Singh ${ }^{5}$ \\ ${ }^{1}$ Department of Ophthalmology, LLRM Medial College, Meerut, Uttar Pradesh, India. ${ }^{2}$ Department of Ophthalmology, \\ LLRM Medial College, Meerut, Uttar Pradesh, India. ${ }^{3}$ Department of Ophthalmology, LLRM Medial College, Meerut, \\ Uttar Pradesh, India. ${ }^{4}$ Department of Ophthalmology, LLRM Medial College, Meerut, Uttar Pradesh, India. \\ ${ }^{5}$ Department of Ophthalmology, LLRM Medial College, Meerut, Uttar Pradesh, India.
}

\section{ABSTRACT}

\section{BACKGROUND}

Dry eye is increasingly becoming a major concern amongst the general population because of the discomforting symptoms it leads to as well as amongst the ophthalmologists who face a diagnostic dilemma because of lack of standardization. It, therefore, becomes important for health personnel to assess the burden of the disease in the population.

\section{METHODS}

This study was conducted in the Upgraded Department of Ophthalmology, LLRM Medical College, Meerut, from June 2017 to May 2018. The study was done to survey the prevalence of dry eye among the patients aged above 20 years presenting to the outpatient department with the symptoms suggestive of dry eye. The patients underwent a holistic series of subjective and objective assessment techniques to determine the prevalence, distribution of the various types of dry eye disease, association of the various known risk factors and frequency of symptoms.

\section{RESULTS}

The prevalence of dry eye in Meerut district is $40.9 \%$. Females $(44.2 \%)$ are more affected than males (35.9\%). Evaporative type (43.1\%) dry eye is the most common in this part of the country followed by the mixed type $(35.4 \%)$. The farmers and labourers $(64.2 \%)$ are the most prone occupations followed by factory workers $(37.7 \%)$ and the maximally affected age group is 60-69 years. Itching is the most common presenting complain.

\section{CONCLUSIONS}

Meerut district has a significant burden of dry eye disease. Risk of dry eye increases with increasing age, exposure to dry and hot climate. Though smokers seem to have an increased risk, this is not statistically significant. Diabetes and hypertension, the two most common systemic illnesses in the presenting population were not found to be statistically significant in terms of increased risk. Wider studies are needed to confirm these findings. By providing more emphasis on the importance of seeking professional help for symptoms of dry eye through public education, we can offer significant relief and perhaps provide a better quality of life.

\section{KEY WORDS}

Dry Eye, Prevalence, Evaporative, Occupation, Age, Climate, Smokers, Diabetes, Hypertension
Corresponding Author: Dr. Jaishree Dwivedi, \#112-A, Ansal Town, Mudepuram Bypass, Meerut, Uttar Pradesh, India. E-mail: drjaishreeduriveda@gmail.com

DOI: $10.14260 / \mathrm{jemds} / 2019 / 734$

Financial or Other Competing Interests: None.

How to Cite This Article:

Attri S, Dwivedi J, Mithal S, et al. Dry eyestudy of prevalence, associated risk factors and frequency of symptoms in Meerut District. J. Evolution Med. Dent. Sci. 2019;8(45):3382-3386, DOI: $10.14260 / j e m d s / 2019 / 734$

Submission 07-07-2019,

Peer Review 24-10-2019,

Acceptance 31-10-2019,

Published 11-11-2019. 


\section{BACKGROUND}

Dry eye disease (DED) or keratoconjunctivitis sicca (KCS), is one of the most common ophthalmologic conditions. According to the International Dry Eye Work Shop (DEWS) in 2007,1 dry eye is defined as a multifactorial disease of the tears and ocular surface that results in symptoms of discomfort, visual disturbance, and tear film instability with potential damage to the ocular surface. It is accompanied by increased osmolarity of the tear film and inflammation of the ocular surface.

\section{Pathophysiology}

Maintaining a healthy and comfortable ocular surface requires stability and renewal of the preocular tear film. Dysfunction of any component by causing alterations in the volume, composition, distribution, and/or clearance of the tear film can lead to ocular surface disease that expresses itself as dry eye. Two mutually reinforcing global mechanisms, tear hyperosmolarity and tear film instability, have been identified. Any subclass of dry eye activates these core mechanisms and explains the features of various forms of dry eye. Tear hyperosmolarity is regarded as the central mechanism causing ocular surface inflammation, damage, and symptoms, and the initiation of compensatory events in dry eye. It can arise from either low aqueous flow or excessive tear film evaporation, or a combination thereof. Hyperosmolar tears can damage the ocular surface epithelium by activating an inflammatory cascade in the epithelial surface cells and releasing inflammatory mediators such as the MAP kinases and NFKB signalling pathways and the generation of inflammatory cytokines (e.g., IL- $1 \alpha$, IL-1 $\beta$, TNF- $\alpha$ ) and MMPs, which arise from or activate inflammatory cells at the ocular surface.

These inflammatory events lead to apoptotic death of surface epithelial cells, including goblet cells, and secondary lacrimal dysfunction. Tear film instability can arise secondary to hyperosmolarity, or can be the initiating event (e.g., lipid layer abnormalities in meibomian gland disease). Tear film instability results in increased evaporation, which contributes to tear hyperosmolarity. Regardless of the initiating event or aetiology, inflammation is usually a key factor in perpetuating DED. Chronic inflammation may subsequently result in lacrimal gland insufficiency, reduced corneal sensation (Long-term effects of inflammatory mediators on sensory nerve terminals supplying the ocular surface) and morphological changes in the sub-basal nerve plexus, and decreased reflex activity including reflex tearing and blinking, leading to increased evaporation and tear film instability. These postulated interactions, occurring over time, may explain the overlap of findings in dry eyes regardless of the underlying aetiology, and reinforce the general concept of a vicious circle in which widely varying influences combine to cause dry eye with a complex profile. Dry eye causes a significant impact on the everyday life, which indirectly have an effect on the overall economy of a nation. ${ }^{2}$ It therefore becomes important to have an assessment of the actual burden of the disease in a given region.
We wanted to estimate the burden of dry eye disease in Meerut District, classify patients according to aqueous tear deficiency (ATD) evaporative dry eye (EDE) and assess the frequency of risk factors of dry eye disease in Meerut District.

\section{METHODS}

The study was conducted in the Upgraded Department of Ophthalmology, LLRM Medical College, Meerut from June 2017 to May 2018 after taking approval from the Institutional Ethical committee. It was a hospital based cross sectional study. Patients were selected from the OPD. Informed consent was obtained.

\section{Inclusion Criteria}

- Symptoms of dry eye for more than 1 month.

- 20 years and older.

- $\quad$ Either sex.

\section{Exclusion Criteria}

- Patients not willing.

- Current ocular infection, inflammation or acute allergic conjunctivitis.

- Patients who need emergency care.

- Patients unable to follow the instruction.

\section{Patient Information}

The following information about the patients was obtained

1. Environmental exposure (sunlight, dust, wind, environmental pollutants): Occupation- outdoor or indoor

2. Smoking - Current or not.

3. Exposure to air condition - Yes/No.

\section{Ocular History}

- Use of contact lens.

- Use of topical medication - beta blockers, anti histaminics, antibiotic steroid combination, drops containing benzalkonium chloride (BAC).

\section{Medical History}

Information on various medical conditions and complains.

- Diabetes.

- Arthritis.

- Thyroid problem.

- Acne.

\section{Use of Systemic Medication}

- Antihypertensive.

- Anti-diabetic.

- Anti-histaminics.

- Diuretics.

- GI ulcer medication.

\section{Assessment Technique}

1. Symptoms Based Assessment- Two questionnaires were used- Dry eye questionnaire 5 (DEQ-5) and Ocular surface disease index.

2. Objective Assessment- Measurements taken- 1. Tear meniscus height (TMH), 2. Tear film break time (TBUT), 3. 
Fluorescein staining (Classified by NEI protocol), 4. Lissamine green stain (Van Bijsterveld Score), 5. Schirmer's test. Assessment of meibum quality on slit lamp examination.

\section{Methodology}

318 patients attending the eye OPD, meeting the inclusion criteria were selected. History of systemic diseases, ophthalmic history treatment history was taken. Systemic and ocular examination was done. These patients were handed over the two dry eye questionnaires (OSDI and DEQ 5) which had questions pertaining to the symptoms of dry eye. Scoring of the patients was done and the scores ranged as follows: OSDI -0 to 100 and the OSDI score $\geq 12$ was taken as positive for dry eye disease. DEQ: $5-0$ to 22 and the score $\geq$ to 6 was taken as positive 3,4 for dry eye disease. This gave the subjective burden of the disease. The Participants then underwent a comprehensive examination test sequence following the DEWS subcommittee diagnostic steps. TBUT was performed before the other dry eye tests, to avoid any untoward interference followed by ocular surface staining. The Schirmer's test was performed last so that ocular irritation by the test strip would not interfere with other examination results. The tests were done under room temperature condition in order and at 10 minutes interval to minimize reflex tearing and ocular surface changes secondary to testing. In those already using tear substitutes, dry eye tests were performed after overnight discontinuation of medication.

\section{Diagnosis of Dry Eye}

OSDI Score $\geq 12$ and DEQ- 5 Score $\geq 6$ (Subjective Assessment/Symptomatically Dry Eye)

\section{Plus, any 3 out of 5}

1. Tear meniscus height $<0.25 \mathrm{~mm}$.

2. Tear film break up time $<10$ seconds.

3. Ocular surface staining positive for dry eye (Score $>$ or $=1$ ).

4. Schirmer's test $<15 \mathrm{~mm}$.

5. Meibomian gland dysfunction present (Score $>$ or $=1$ ).

\section{Classification of Dry Eye ${ }^{1,5}$}

Aqueous Tear Deficiency (ATD)

1. TBUT $<10$ sec.

2. Ocular surface dye staining pattern: inferior cornea and bulbar conjunctiva.

3. Tear meniscus $<0.25 \mathrm{~mm}$.

4. Schirmer's strip test $<15 \mathrm{~mm}$.

5. Presence of risk factors for ATD (From those included in the study)

\section{Evaporative Tear Deficiency (ETD)}

1. TBUT $<10 \mathrm{sec}$.

2. Ocular surface staining score: interpalpebral cornea and bulbar conjunctiva.

3. Presence of meibomian gland disease.

4. Presence of risk factors for ETD (From those included in the study)

\section{Mixed Type}

Presence of characteristics of ATD and ETD (Either or all of the criteria) at the same time.

\section{Statistical Analysis}

Sample size calculation- The various studies are conducted on the prevalence dry eye. Keeping in mind the study done by and Gupta et al Moushumi Majumder et al, Ravi Ranjan et al and considering the prevalence of $29.25 \%$ at $95 \%$ confidence interval with $5 \%$ absolute precision, the sample size is as follows.

$\mathrm{n}=(1.96) 2 \mathrm{pq} / \mathrm{d} 2$

Where $\mathrm{n}=$ sample size

$\mathrm{d}=$ absolute precision

$\mathrm{p}=$ prevalence

$\mathrm{q}=(1-\mathrm{p})$

$\mathrm{n}=(1.96) 2 \mathrm{p}(1-\mathrm{p}) / \mathrm{d} 2$

$=3.84 \times .2925(1-2925) /(0.5) 2$

$=3.84 \times .2925 \times .7075 / .0025$

$=318$

Number of patients diagnosed with dry eye $=130$

Total number of patients included in the study $=318$

Prevalence $=$ Number of patients diagnosed with dry eye/ total number of patients included in the study.

$=130 / 318$

$=40.9 \%$

The prevalence of dry eye in Meerut district is $40.9 \%$. With the maximum patients having evaporative type (43.1\%) followed by the mixed type $(35.4 \%)$ and the aqueous tear deficiency (21.5\%) being the least common. Prevalence of dry eye increased progressively with age with age group 60-69 years showing the maximum, that is, $54.6 \%$. Prevalence among females $(44.2 \%)$ is greater than males $(35.9 \%)$. The farmers and labourers (64.2\%) are maximally affected followed by factory workers $(37.7 \%)$. This finding is statistically significant ( $p$ value $=0.001$ ). None of the risk factors included in the study that may attribute to dry eye were found to be statistically significant in this study. Itching was the commonest reported symptom (72\%) followed by watering $(65 \%)$.

\section{RESULTS}

\begin{tabular}{|c|c|c|}
\hline Type & Number of Patients & Prevalence (\%) \\
\hline Evaporative & 56 & 43.1 \\
\hline Aqueous deficiency & 28 & 21.5 \\
\hline Mixed & 46 & 35.4 \\
\hline Total & $\mathbf{3 1 8}$ & $\mathbf{1 0 0}$ \\
\hline \multicolumn{2}{|c|}{ Table 1. Distribution of Dry Eye According to Type } \\
\hline
\end{tabular}

\begin{tabular}{|c|c|c|c|}
\hline Age (in Years) & No. of Subjects & Dry Eye & Prevalence (\%) \\
\hline $20-29$ & 25 & 7 & 28.0 \\
\hline $30-39$ & 32 & 12 & 37.5 \\
\hline $40-49$ & 39 & 13 & 33.3 \\
\hline $50-59$ & 71 & 26 & 36.6 \\
\hline $60-69$ & 86 & 47 & 54.6 \\
\hline $70-79$ & 52 & 21 & 40.4 \\
\hline $80-89$ & 10 & 3 & 30 \\
\hline $90-99$ & 3 & 1 & 33.3 \\
\hline \multicolumn{4}{|c|}{ Table 2. Age Distribution } \\
\hline
\end{tabular}

\begin{tabular}{|c|c|c|c|}
\hline Gender & $\begin{array}{c}\text { Number of } \\
\text { Patients }\end{array}$ & $\begin{array}{c}\text { Dry Eye } \\
\text { Present }\end{array}$ & $\begin{array}{c}\text { Prevalence of Dry } \\
\text { Eye (\%) }\end{array}$ \\
\hline Male & 128 & 46 & 35.9 \\
\hline Female & 190 & 84 & 44.2 \\
\hline \multicolumn{3}{|c|}{ Table 3. Sex Distribution } \\
\hline
\end{tabular}




\begin{tabular}{|c|c|c|c|}
\hline Occupation & Exposed & Affected & Prevalence (in \%) \\
\hline Farmers/Labourer & 67 & 43 & 64.2 \\
\hline Factory worker & 61 & 23 & 37.7 \\
\hline Office worker & 40 & 15 & 37.5 \\
\hline Home Makers & 64 & 23 & 35.9 \\
\hline Students & 30 & 7 & 23.3 \\
\hline Non-Specific & 56 & 19 & 33.9 \\
\hline \multicolumn{2}{|c|}{ Table 4. Distribution of Cases According to Occupation } \\
\hline
\end{tabular}

\begin{tabular}{|c|c|c|}
\hline Risk Factors & Exposed & Affected \\
\hline Smoking & 123 & 49 \\
\hline Systemic Disease & 82 & 29 \\
\hline Topical Medication & 50 & 18 \\
\hline Systemic Medication & 58 & 22 \\
\hline Contact Lens & 5 & 3 \\
\hline Air conditioning & 65 & 27 \\
\hline \multicolumn{2}{|c|}{ Table 5. Distribution of Cases According to Risk Factors } \\
\hline
\end{tabular}

\section{DISCUSSION}

Past Indian studies have shown the prevalence of dry eye ranging from $10.8 \%$ to $57.1 \%$. This is probably because of two factors: first the geographical location of the study population and secondly there is no standardization of the selected population, dry eye questionnaires results, objective tests and dry eye diagnostic criteria. The predominant type of dry eye was evaporative dry eye $(43.1 \%)$ followed by the mixed pattern (35.4\%). Effect of meibomian gland dysfunction in all age groups could be the reason for evaporating exceeding the aqueous deficient type.6-10 $\mathrm{We}$ found that dry eye prevalence increased progressively with age.11-14 This trend can be explained by the fact that with increasing age there is an increase in lacrimal gland ductal pathology that could promote lacrimal gland dysfunction by its obstructive effect, also there is decrease in androgen levels. ${ }^{15,16}$ In our study we found that there was a greater prevalence of dry eye among females than males. ${ }^{17-19}$ This difference is statistically significant. This could be explained by the fact that hormonal influences in the pathogenesis of dry eye $\mathrm{e}^{20-22}$ have a greater bearing on females than males. Sex hormone levels may influence both the lacrimal and meibomian glands. The increased prevalence in females may also have been due to higher number of females with dry eye symptoms seeking advise for ocular problems. This study, however, does not comment on the pre and postmenopausal prevalence of dry eye among females. Farmers/labourers (64.2\%) had maximum prevalence.23,24 The probable explanation for this trend could be the increased exposure to precipitating or causative environmental conditions ${ }^{25}$ (Sunlight/high temperatures/windy conditions/dirt/dust/smoke) among those involved in field jobs. Considerable prevalence among the young involved in office work $(40.00 \%)$, could be due to increased screen viewing time which reduces blinking rate, ${ }^{26-28}$ exposure to air conditioners for long hours, exposure to air pollution. Smokers had a dry eye prevalence of $39.8 \%$ which is not statistically significant.

Further confirmatory large-scale studies are needed to establish the role of smoking. In this study $35.3 \%$ of the patient had history of some systemic disease. Diabetes and hypertension were the most frequently encountered diseases. Second most frequently encountered was arthritis. ${ }^{29,30}$ The statistical correlation of diabetes mellitus and hypertension, in this study, was not significant. Consistent with the association with the systemic diseases $37.9 \%$ of the patient reported taking systemic medication for long duration. Amongst the associated drugs antihypoglycaemic, amlodipine topped the list. Others included thyroxin, non-steroidal antiinflammatory, $\mathrm{H} 1$ inhibitors. $36 \%$ had a history of topical medication (Anti-glaucoma, anti-histaminics, steroid antibiotic combination) although none of these drugs showed statistical significance in this study as a risk factor. In our study the most frequently encountered symptom was itching (72\%) followed by watering (65\%).

\section{CONCLUSIONS}

Dry eye is a major tear film related disorder that affects millions of people worldwide. It is a distressing problem which is often overlooked and is frequently underdiagnosed. The multifactorial etiopathogenesis and lack of specificity of symptoms explain why the clinical diagnosis of dry eye remains a challenge. Also, there is poor association between the signs and symptoms of dry eye. The main limitation of the study is that it is a hospital-based study. Sample size and duration of study was small thus the study may not be representative for the entire population.

\section{REFERENCES}

[1] The definition and classification of dry eye disease: report of the Definition and Classification Subcommittee of the International Dry Eye Work Shop (2007). Ocul Surf 2007;5(2):75-92.

[2] Pflugfelder SC. Prevalence, burden and pharmacoeconomics of dry eye disease. Am J Manag Care 2008;14(3 Suppl):S102-S6.

[3] Schiffman RM, Christianson MD, Jacobsen G, et al. Reliability and validity of the ocular surface disease index. Archives of Ophthalmology 2000;118(5):615-21.

[4] Grubbs JR Jr, Tolleson-Rinehart S, Huynh K, et al. A Review of quality of life measures in dry eye questionnaires. Cornea 2014;33(2):215-8.

[5] Basak SK. AIOS CME Program on dry eye disease. All India Ophthalmological Society Publication, July 2013.

[6] Banik AK, Adhikari S, Datta S, et al. Estimating the prevalence of dry eye among patients attending a tertiary ophthalmology clinic in Eastern India. Asian Pacific Journal of Health Sciences 2018;5(1):202-7.

[7] Lemp MA, Nichols KK. Blepharitis in the United States 2009: a survey-based perspective on prevalence and treatment. Ocul Surf 2009;7(Suppl 2):S1-S14.

[8] Phadatare SP, Momin M, Nighojkar P, et al. A comprehensive review on dry eye disease: diagnosis, medical management, recent developments and future challenges. Advances in Pharmaceutics 2015;2015:704946.

[9] Messmer EM. The pathophysiology, diagnosis and treatment of dry eye disease. Deutsches Arzteblatt International 2015;112(5):71-82. 
[10] Stapleton F, Garrett Q, Chan C, et al. The epidemiology of dry eye disease. Dry Eye 2015: p. 21-9.

[11] Sahai A, Malik P. Dry eye: prevalence and attributable risk factors in hospital-based population. Ind J Ophthalmol 2005;53(2):87-91.

[12] Majumder M, Manna B, Devi M. A clinical study on prevalence of dry eye disease among the patients attending O.P.D in a tertiary care hospital in Assam. International Journal of Science and Research (IJSR) 2016;5(11):1681-4.

[13] Gupta J, Prasad R, Jain P, et al. Estimating the prevalence of dry eye among Indian patients attending a tertiary ophthalmology clinic. Ann Trop Med Parasitol 2010;104(3):247-55.

[14] Moss SE, Klein R, Klein BE. Prevalence of and risk factors for dry eye syndrome. Arch Ophthalmol 2000;118(9):1264-8.

[15] Schaumberg DA, Buring JE, Sullivan DA, et al. Hormone replacement therapy and dry eye syndrome. JAMA 2001;286(17):2114-9.

[16] Sullivan DA, Wickham LA, Rocha EM, et al. Influence of gender, sex steroid hormones and the hypothalamic pituitary axis on the structure and function of the lacrimal gland. Adv Exp Med Biol 1998;438:11-42.

[17] Chakma AK, Roy M, Varghese J. Dry eye - a clinical study in a hospital based population. Indian Medical Gazette 2013: p. 319-22.

[18] Galor A, Kumar N, Feuer W, et al. Environmental factors affect the risk of dry eye syndrome in a United States Veteran population. Ophthalmology 2014;121(4):9723.e1.

[19] Abdelaziz MM, Fahim SA, Mousa DB, et al. Effects of computer use on visual acuity and colour vision among computer workers in Zaria. Eur J Sci Res 2009;35(1):99105.

[20] Nagler RM, Pollack S. Sjögren's syndrome induced by estrogen therapy. Semin Arthritis Rheum 2000;30(3):209-14.
[21] Hikichi T, Yoshida A, Fukui Y, et al. Prevalence of dry eye in Japanese eye centers. Graefes Archive for Clinical and Experimental Ophthalmology 1995;233(9):555-8.

[22] Versura P, Cellini M, Torreggiani A, et al. Dryness symptoms, diagnostic protocol and therapeutic management: a report on 1,200 patients. Ophthalmic Res 2001;33(4):221-7.

[23] Lekhanont K, Rojanaporn D, Chuck RS, et al. Prevalence of dry eye in Bangkok, Thailand. Cornea 2006;25(10):1162-7.

[24] Sendecka M, Baryluk A, Polz-Dacewicz M. Prevalence and risk factors of dry eye syndrome. Przegl Epidemiol 2004;58(1):227-33.

[25] Viso E, Rodriguez-Ares MT, Gude F. Prevalence of and associated factors for dry eye in a Spanish adult population (the Salnes Eye Study). Ophthalmic Epidemiol 2009;16(1):15-21.

[26] Lu P, Chen X, Liu X, et al. Dry eye syndrome in elderly Tibetans at high altitude: a population-based study in China. Cornea 2008;27(5):545-51.

[27] Pathak AK, Lakra MD, Gupta RK. Study to assess dry eye among patients of a tertiary care hospital in Jharkhand. International Journal of Contemporary Medical Research 2017;4(9):1861-4.

[28] Choudhary P, Chalisgaonkar C, Lakhtakia S. Dry eye prevalence and attributable risk factors in the eastern Madhya Pradesh. Int J Med Sci Public Health 2015;4(11):1556-60.

[29] Chisti MA, Rao AT, Siddhartha PS. Screening for dry eye diseases in out-patients presenting at a tertiary care hospital: a clinical study. Indian Journal of Applied Research 2015;5(12):122-4.

[30] Shah S, Jani H. Prevalence and associated factors of dry eye: our experience in patients above 40 years of age at a tertiary care centre. Oman Journal of Ophthalmology 2015;8(3):151-6. 